as compounds in the nature of salts. Qualitative tests with liquid sulphur dioxide as a solvent showed a much higher degree of molecular conductivity.

From the experimental results presented in this paper it is seen that tritolylmethane is, in all respects, analogous to triphenylmethane. The presence of so many methyl grotps lowers greatly the melting-point of the hydrocarbon, so that even in a freezingmixture it remains viscous. The two carbinols, those of tritolylmethane and of triphenylmethane, behave similarly toward halogen acids, acetylchloride, reducing agents, etc. The tritolylcarbinolhalides, like the corresponding triphenyl componnds, react readily with water, alcohol, halogens, ammonia and amines. With halide salts, such as mercuric chloride, ferrous chloride and zinc chloride, aouble salts are formed. ${ }^{1}$ Also, as has been shown, ${ }^{2}$ they react with zinc and silver in neutral solvents, giving rise to an extremely unsaturated substance, which, on exposure to air, forms tritolylmethyl peroxide, $\left(\mathrm{CH}_{3} \mathrm{C}_{6} \mathrm{H}_{4}\right)_{3} \mathrm{COOC}\left(\mathrm{C}_{6} \mathrm{H}_{4} \mathrm{CH}_{3}\right)_{3}$, the reaction being strictly analogous to that of the triphenylhalogenmethanes.

ANN ARBOR, MICHIGAN,

July, 1904 .

\title{
THE CHEMICAL COMPOSITION OF MAPLE-SYRUP AND MAPLE-SUGAR, METHODS OF ANALYSIS, AND DETECTION OF ADULTERATION.
}

By JULiUS HORTVET.

Received August 26, 1904.

By A rough classification, accountable by the fact that sucrose constitutes their chief ingredient, so-called maple-syrup and maple-sugar have long been classed with products obtained from sugar-cane, sugar-beet and sorghum. The statement that the sugar of the maple sap is identical in composition with that of the sugar-cane has been currently accepted, hence it has been concluded that chemical methods are helpless as a means of distinguishing the syrup or sugar prepared from the sugar-maple from like products prepared from the sugar-cane. Commercial interests have taken advantage of the unsatisfactory state of chemical knowledge regarding maple products, and have been active in

1 This Journat, 24, 624 (1902).

2 Ber.d. chem. Ges., 37, 1628 (1904). 
enforcing upon the popular mind the belief that pure maple-sugar is chemically identical with the well-known refined granulated sugar. Contrary to absurd opinions and interested claims, however, it is obvious that, beyond the point of identity as regards their sucrose content, so-called cane-sugar and maple-sugar are very divergent in composition and properties.

Maple-sap is essentially a dilute solution of sucrose, carrying, also, small amounts of proteids, organic acids (mainly malic), mineral matter (chiefly lime and potash) and traces of reducing sugars. ${ }^{1}$ During the boiling-down process some of the proteids are coagulated and rise to the surface, where they are removed by skimming, while a considerable amount of the mineral matter (so-called "nitre" or simple dirt) is deposited at the bottom of the evaporator. The syrup, after being drawn, may be further clarified by filtering hot through felt strainers or by sedimentation. A product intended for use as syrup is commonly boiled down to a density of I I pounds of syrup per gallon; if it is to be made into sugar, the syrup is boiled to a concentration such that it will harden on cooling. As is well known, the value of maple-sugar is out of proportion to the saccharine matter which it contains, and is due to the peculiar pleasant flavor clerived from certain minor ingredients carried in the sap. The nature of these flavoring substances has not been definitely determined, but that they are not wholly volatile is shown by the fact that they remain in the syrup during the process of concentration and may be retained in the sugar for a considerable time. The distinctly agreeable odor that accompanies the evaporation of maple-sap is familiar to any one who has visited an orchard during the sugar season. The wide range in color, from very light to very dark, characteristic of maple-syrups and sugars is attributable to various causes, chief among which are location and character of soil, time of season, and care taken in handling and boiling the sap. The first run of sap produces a much lighter-colored syrup and sugar than the later runs, which not only yield darker products, but impart flavors sometimes unpleasant to the taste. The first run is considered by all producers as by far the best for making a first-class product. Color is, however, not a safe criterion as to quality or purity, and has little infuence upon prices commanded in the general market, as it has long been suspected that very little of the pure article eventually reaches the consumer.

"Vt. Agr. Exp. Sta., Bull. I03, "The Maple Sap Flow," p. 47. 
It has long been a matter of common report that there are sold on the market large quantities of alleged maple-syrups which are fabrications composed only in part of maple-syrup, or, as has often been the case, are entirely free from any maple product whatever. The requisite maple flavor has been imparted to such syrups, it is said, by mixing them with an extract prepared from hickory bark and sold extensively under the name of "mapleine." As claimed by its inventor, "The effect of the extract or decoction is to give to the syrup the flavor of the maple, producing a syrup which cannot be distinguished from genuine maple-syrup." 1 The simple practice of flavoring syrups with corn-cob infusions has, so far as known, probably not extended seriously beyond the bounds of rural communities or the domestic kitchen. There has recently been reported a process of preparing imitation maple-syrup, which consists in distilling maple or hickory chips with steam, adding sugar to the distillate, boiling down to the required density, then adding caramel if necessary. Various other processes, concoctions, flavors and essences have presented themselves from time to time, but these, in most instances, have been of such a character as not to merit serious attention. The use of so-called corn-syrup, or starch glucose, as an adulterant of maple-syrup has been practiced quite extensively for many years, but this form of adulteration, while very profitable to the manufacturer, has yielded an inferior article and one which could easily be detected by the chemist, if not by the consumer.

Within the past fifteen years more or less complete analyses of maple products have been made and reported, notably by analysts of the United States Department of Agriculture, ${ }^{2}$ the Canada Inland Revenue Department, ${ }^{8}$ the Connecticut Agricultural Experiment Station at New Haven, ${ }^{4}$ and the Illinois State Food Commission:" These analyses, with the exception of those reported from Canada, show little or no attempt to determine the properties of samples of known purity, and beyond the point of reporting adulteration with starch glucose, all analysts are cautious and seem to be of the opinion that it is impossible to say in regard to

1 U. S. Dept. Agr., Bul1. 13, 710-712, 1892.

2 U. S. Dept. Agr., Bull. 13, I892.

3 Inland Rev. Dept., Can., Bull. 1896, Part III.

4 Conn. Agr. Expt. Sta., New Haven, 2oth Annual Rep., I8g6.

5 Ill. Food Com., 2nd Annual Rep., Igor. 
most samples whether they are spurious or genuine. The analysis of commercial maple-syrups has, therefore, in recent years, been confined chiefly to the detection of starch glucose.

Of the small number of syrups examined in the laboratory of the Minnesota Dairy and Food Department during 1902 about Io per cent. were found to be glucose mixtures, and during the progress of the work in the year following it soon became apparent that a very large number of the alleged maple-syrups, not classed among the glucose mixtures, were, in all probability. maple-syrups more or less diluted with common cane-syrup. A complete chemical analysis of a large number of samples of known purity alongside with the analysis of a corresponding. number of commercial products seemed to be the necesssary course in order to differentiate more closely the true from the false. During the seasons of 1903 and 1904 about fifty samples of known purity, fairly representing the principal maple-sugar producing regions of the United States, have been collected. The results of the analysis of these, together with results obtained on syrups and sugars bought in the open market, are shown in the following tables. The known pure syrups and sugars include (I) Minnesota syrups obtained direct from the producers by inspectors of this Department: (2) samples obtained by the chemists of this Department through relatives or friends in Eastern States; (3) samples obtained by other persons through reliable sources. Very nearly all samples have been furnished with the understanding that they were to be used for the purpose of a special investigation, and in many cases a written statement has been given in answer to questions regarding the methods employed in making pure maple-syrup and pure maple-sugar.

The descriptive terms used in the tables are for the present purpose general, no attempt being macle to give exact clates of manufacture or to state, in detail, the condition or properties of the samples. It is considered sufficient simply to give year, time of season (early, middle or late), and a word as to the appearance, i. e., whether light, medium or dark. In Table I, syrup No. 4 Penn, was reduced to a small residue, composed largely of sedimentary material, at the time of the protein and malic acid determinations. Samples Nos. 59 Minn., 60 Minn., 6r Minn., and I N.Y. were spent before the determinations could be completed. The New York syrups were unusually well clarified and were made 
with great care, especially for this investigation. The Minnesota, Pennsylvania and Connecticut samples were of average good quality. In Table IV, stugar No. I N. Y. was of uncommonly light shade, and when pulverized might have been mistaken for a fair grade of refined cane-sugar. Samples Nos. A Vt., B Vt. and $\mathrm{C} \mathrm{Vt}$. were of somewhat inferior grade and were evidently made with little attempt at clarifying. All other sugars were of good quality, especially $3 \mathrm{~N}$. Y., which came from the same source as the New York syrups above mentioned. Sample No. $3 b$ Penn. was too small to permit of a complete analysis.

While undergoing analysis the syrups were kept in cans or bottles in the refrigerator. In a few cases where it seemed necessary, the tendency to fermentation was overcome by the use of antiseptics. Formaldehyde, salicylic acid and benzoic acid were tried, each with fairly good results, though it was recognized that in certain contingencies each might be objectionable, formaldehyde, for example, on account of its reducing action on the Fehling solution, being inadmissible in cases where reducing sugars were yet to be determined. To insure a satisfactory keeping of the sugar samples, it was found advisable to break them up in lumps, then place them in wide-mouthed bottles and keep tightly corked. In sampling the syrups for analysis the clear liquid was taken, avoiding the sedimentary material. When a sample could not be clarified by sedimentation, it was filtered through ordinary filter-paper under pressure. In sampling a sugar, a portion of the mixed shavings, obtained from several pieces, was taken.

METHODS OF ANALISIS.

Specific Gravity.-The syrup was cooled to $15.5^{\circ} \mathrm{C}$. and the determination made with a specific gravity hydrometer graduated from $I, 200$ to $I, 400$.

Moisture.-Three grams of the sample were weighed into a flat-bottomed glass dish having a diameter of about $8 \mathrm{~cm}$. and provided with a short glass stirring rod. In the case of a sugar the sample was added in a finely shaven condition, and in every case the sample was so placed as to cover the bottom of the dish evenly in a thin layer. The sample was dried at the temperature of boiling water, stirred at two-hour intervals until brought to a powdered condition, then at the end of eight hours cooled in a desiccator and weighed. The sample was returned to 


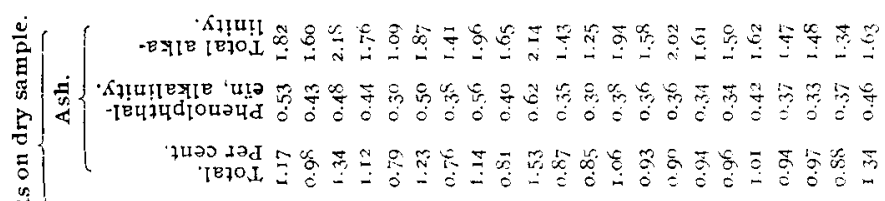



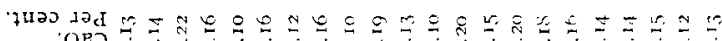
oes o 过



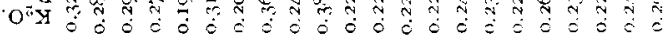
งไ!u!l

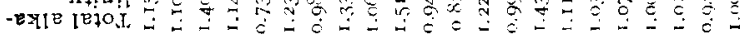

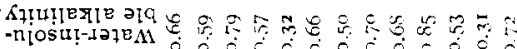

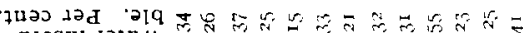

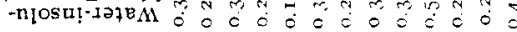

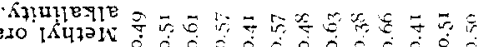

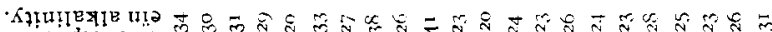

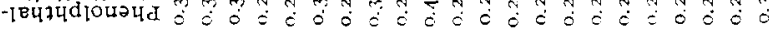



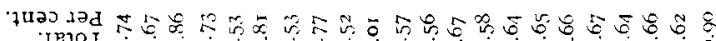

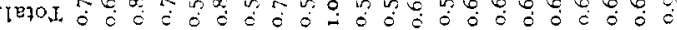

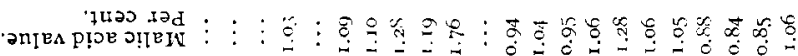

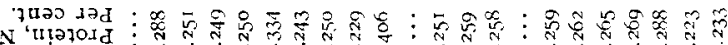

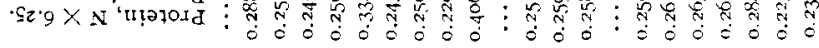

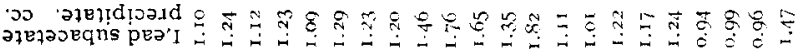

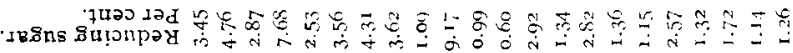

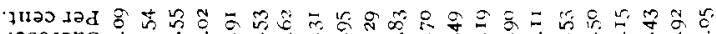

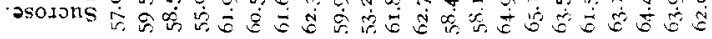

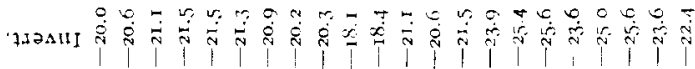



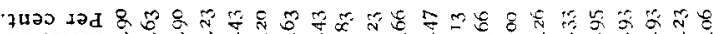

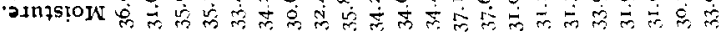



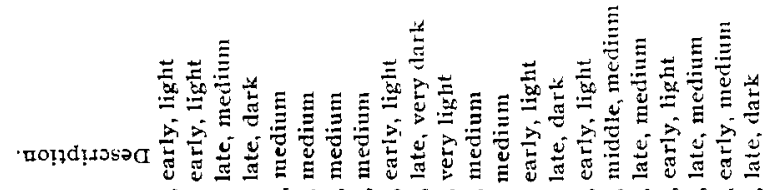



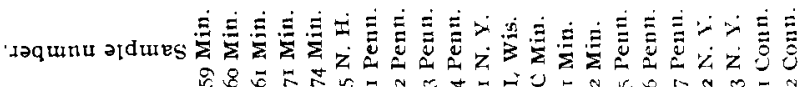




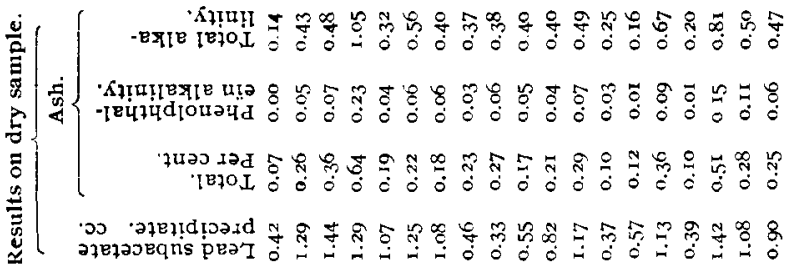

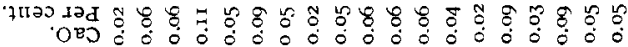



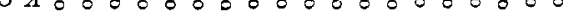

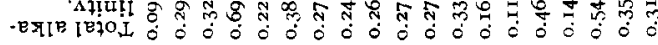



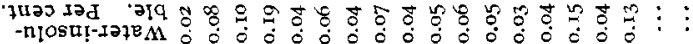

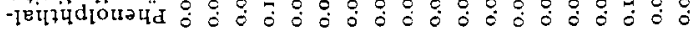

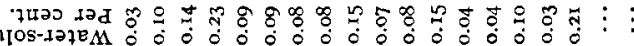

.

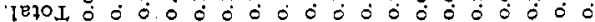

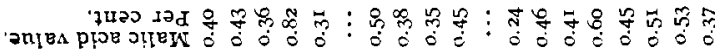
7uas 1ad

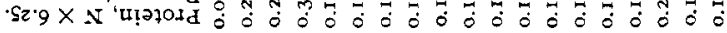

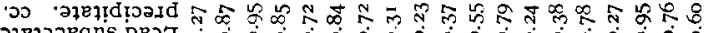

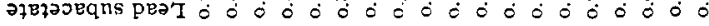

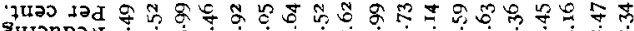

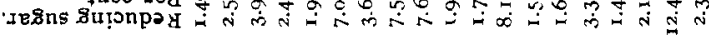


asolons



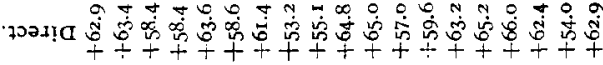

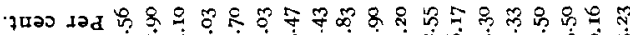

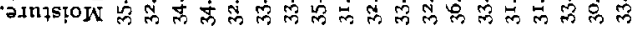

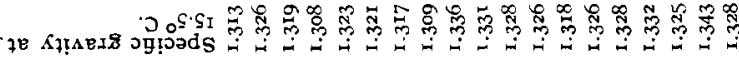

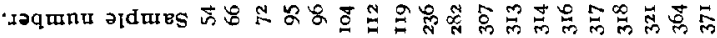




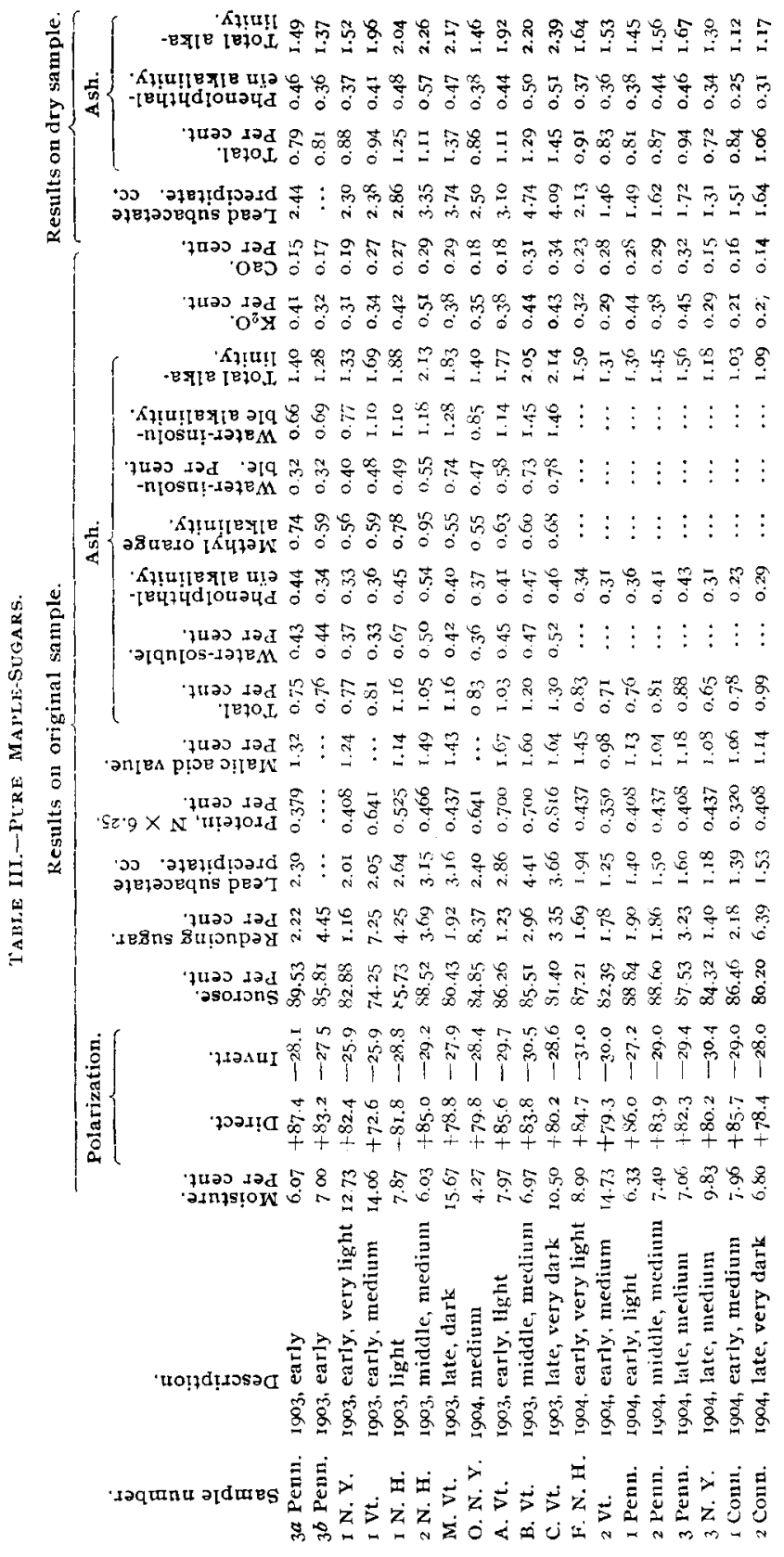



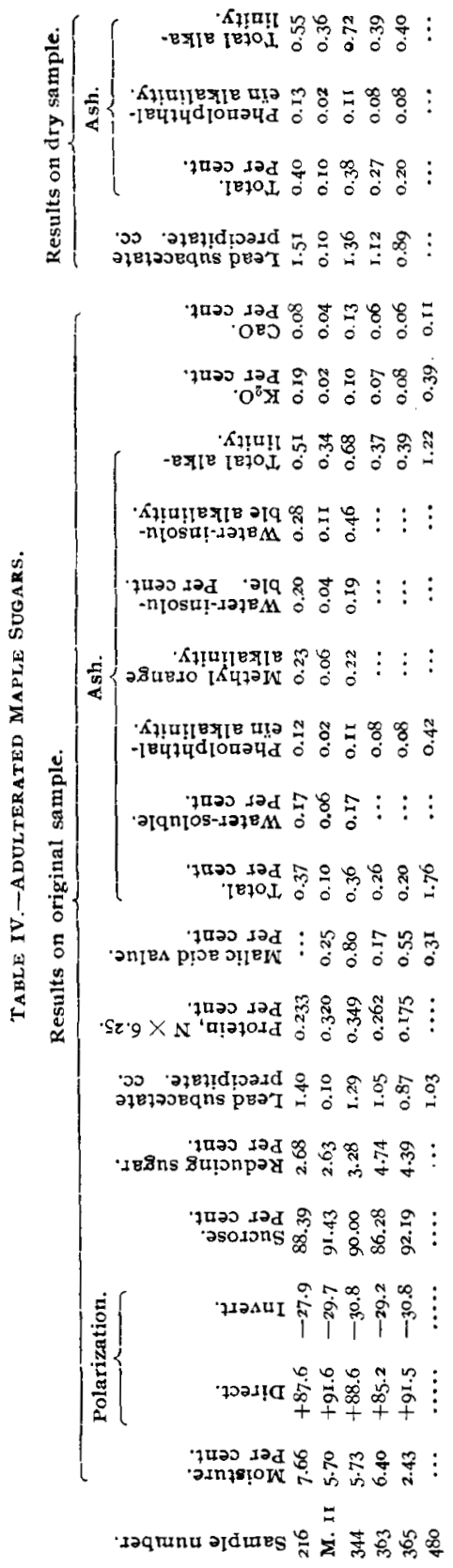
the oven and dried for another two hours. If, on again weighing, there was noted only a slight change in weight, the drying was considered finished; otherwise the drying was continued until the weight was practically constant.

Polarization (Sucrose).-The German official $\operatorname{method}^{\mathbf{1}}$ was used, as recommended on page 57 of the Proceedings of the Association of Official Agricultural Chemists for 1902, and with the modification given on page 230 of the Proceedings for 1903. The alternate official method of inversion without the application of heat is commended. The absence of raffinose may be assunied, and the polarizations should be made in a tube provided with a water jacket, as devised by Landolt, passing a current of water through to maintain a temperature of $20^{\circ} \mathrm{C}$.

Reducing Sugars (Estimated as Dextrose).-The determination was made by the method of Allihn," or, in other words, by the official method of Igor," omitting the clarification with lead subacetate. The solution of the sample was filtered, when necessary, through a dry filter and made up so as to contain approximately I per cent. of reducing sugar. The precipitated copper oxicle was washed with alcohol and ether, dried at $100^{\circ} \mathrm{C}$. for one hour, allowed to cool one-half hour, then weighed as $\mathrm{Cu}_{2} \mathrm{O}$. The clarification with subacetate of lead has been omitted, as it has been found that results on clarified and on unclarified solutions, prepared from the same sample, agree closely.

licad Subacetate Precipitate.-The wide variation in the volumes of the precipitates formed when clarifying maple-sugar and syrup solutions with subacetate of lead has often been noted. It has been observed that more or less copious precipitates were associated with samples of known purity, while in very many cases of known or suspected adulteration with canesugar the precipitates were slight or only equivalent to a mere clondiness. A year ago a method was devised by which these precipitates could be made to occupy definite volumes under fixed conditions. The method, in brief, consists in reducing the precipitate to a compact mass at the bottom of a graduated tube by

1 Wiechmann's "Sugar Anaiysis," p. 45.

2 Bull, 46, U. S. Dept. Agr., Bureau of Chemistry, p. 35.

3 Bull, 65, U. S. Dept. Agt., Bureau of Chemistry, p. 49. 
the use of a centrifugal machine, noting the reading on the tube, applying necessary corrections, and expressing the volume of the precipitate in cubic centimeters and tenths. By means of this method it has been shown that valuable data are readily obtainable regarding the character of suspected samples.

The apparatus consists of a glass tube somewhat suggestive of an inverted Babcock cream test bottle (see cut), and is described as follows:

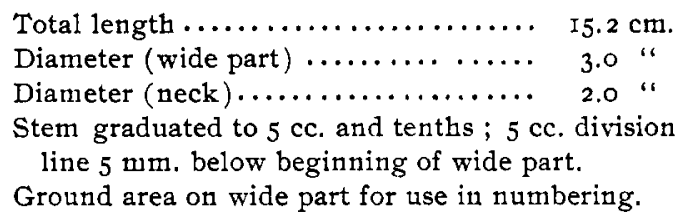

The tube is provided with a holder, which is described as follows :

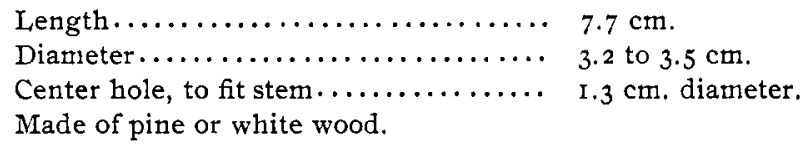

The tube and holder constitute a couple and weigh together about 50 grams. They should be so constructed that when fitted together the bottom end of the tube will be exactly even with the lower surface of the holder. In order to prevent mixing the pieces belonging to a set, each tube should bear a number corresponding with the number of its holder. Also, in a set, each couple, i. e., tube and holder, should be made to balance every other. There should be, as nearly as possible, a balanced load carried at the circumference of the wheel of the centrifuge.

The determination was conducted as follows: Five cc. of syrup or 5 grams of sugar were introduced into the tube, Io cc. of water added, and the contents thoroughly mixed. Time was given in the case of sugar for complete solution.

One-half cc. (Io drops) of alumina cream (prepared as given in Bulletin No. 46, page 39) and I.5 cc. of lead subacetate were 


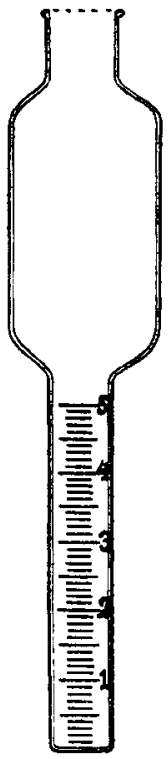

T'ube.


Holder.

Apparatus.

then added and the contents well shaken. The mixture was allowed to stand from forty-five to sixty minutes, occasionally giving the tube a twisting motion to facilitate the settling of the precipitate.

The tube with its holder was then placed in the centrifugal machine and run six minutes (see conditions given below). At the end of six minutes the contents of the tube were examined, and if any material adhered to the sicle of the wider portion, it was loosened by means of a small wire provided with a loop at the end. The tube was returned to the centrifuge and run six minutes longer at the same rate. The volume of the precipitate was noted, estimating o.or cc. as closely as possible. A blank, using water ${ }^{2}$ and the reagents named above. was run as often as seemed necessary in order to be certain as to its value. The blank reading was subtracted from the reading given by the precipitate in each case. In the case of a syrup the result was reduced to the 5-gram basis by dividing by the specific gravity of the sample. If the sugar content of the sample was known, the specific gravity

1 Circular U. S. Dept. Agr, Bureau of Chemistry, giving Hortvet method for examinajon of maple-syrup and sugar.

2 Cane-sugar solution of sp. gr. 1.330 is suggested; the blank would be a trifle higher. 
was found from tables. ${ }^{1}$ Usually I.330 has been found very nearly correct for maple syrup.

The centrifugal machine used in this laboratory has a radius of $18.5 \mathrm{~cm}$., and a speed of 1600 revolutions per minute has been adopted. Calling $\mathrm{M}$ unity in the formula

$$
\mathrm{F}=\frac{\mathrm{M} v^{2}}{r}, \text { then } \mathrm{F}=\frac{v^{2}}{r}, \text { and } v=\sqrt{\mathrm{Fr}}
$$

From the above a numerical expression for $F$ can be computed, then having measured $r$ for a given machine, the value of $v$ and the required number of revolutions per minute can be found.

The results given in Table $\mathrm{V}$ show why a total run of twelve minutes was adopted. Such results can possibly be made to agree more closely under more perfect conditions. The results were abtained on $5 \mathrm{cc}$. samples and have not been reduced to results on the 5-gram basis. The mean blank at the end of twelve minutes was. $0.44 \mathrm{cc}$. Samples designated 100 per cent. pure are from syrups of known purity. Cane-sugar syrup of the same density was added to the other samples in the proportions indicated.

Table V.-Precipitates Obtained by Varying Time of Running.

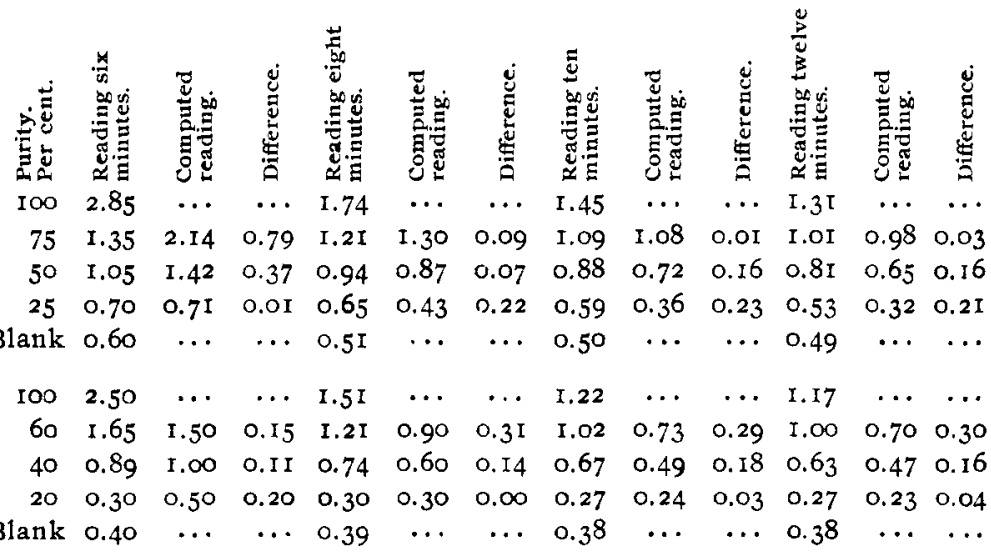

Protein.-Nitrogen was determined by the Gunning method, and the protein was computed as $N \times 6.25$. Three grams of sugar, or in case of syrup, about four grams, were weighed into a $500 \mathrm{cc}$.

1 Bul1. 65, U. S. Dept. Agr., Bureau of Chemistry, Table VI, p. 139. 
digestion flask, the sample treated with Io grams of potassium sulphate and $20 \mathrm{cc}$. of concentrated sulphuric acid, and the material cligested until colorless. After cooling and adding Ioo cc. of water the digestion flask was connected with an apparatus for distilling in a current of steam. ${ }^{1}$ Seventy $\mathrm{cc}$. of a saturated solution of sodium hydroxide were then run into the flask, steam turned on, and the ammonia distilled into too cc. of water containing $5 \mathrm{cc}$. of tenth-normal sulphuric acid. When about i $50 \mathrm{cc}$. of distillate had been collected, the solution was titrated with tenth-normal sodium hydroxide, using cochineal as an indicator. A blank determination was made and the result applied as a correction factor in making the calculations.

Malic Acid $V$ alue.-This determination was made by a modification of the calcium chloricle method of Leach and Lythgoe." Six and seven-tenths grams of the sample were weighed into a $200 \mathrm{cc}$. beaker, and water adcled to make a volume of $20 \mathrm{cc}$. The solution was made slightly alkaline with ammonia, I cc. of a Io per cent. solution of calcium chloride added, then $60 \mathrm{cc}$. of 95 per cent. alcohol. The beaker was covered with a watch-glass and heated for one-half hour on a water-bath, the flame then turned off and the beaker allowed to stand over night. The material in the beaker was then filtered through good quality filter-paper, the precipitate washed with hot 75 per cent. alcohol to freerlon from soluble calcium salt, dried and ignited. From is to $20 \mathrm{cc}$. of tenth-normal hydrochloric acid was added to the ignited residue, the lime thoroughly dissolved by careful boiling, and the excess of acid titrated with tenth-normal sodium hydroxide, using methyl orange as an indicator. One-tenth of the number of cubic centimeters of acid neutralized expresses the result, which, for the present. will be called the "malic acid value."

It is not advisable to filter before adding the alcohol, nor has it been found necessary, as no precipitate appears at that point. Repeated trials have also shown that heating to boiling and filtering immediately after adding calcium chloride and alcohol not only incurs a possible loss of material due to bumping, but gives results which are always lower and are seldom concordant. The method has given satisfactory results on a wide range of samples, yet it is not claimed at the present stage of the investiga-

1 This Journal, 24, 388 (1902).

? $/ b 1 d, 26,360$ (1904). 
tion that the results express absolutely the malic acid present; they are given only as "values" which are shown to be significant. $A s h$.-Ten grams of the sample were weighed in a tared flatbottomed platinum dish of about $7 \mathrm{~cm}$. diameter, heated carefully over an asbestos plate until near the point of charring, then ashed until nearly decarbonized at faint redness over a Chaddock burner, being careful not to heat to fusing. Remaining particles of carbon were removed by cooling, adding a few drops of water, drying over the asbestos plate, then heating over the open flame at dull redness. The operation was repeated, if necessary, the dish then cooled in a desiccator and weighed. The weighings were made as quickly as possible, as the ash absorbs moisture very rapidly.

Alkalinity of Ash; Method (a).-Water was added to the ash in the platinum dish, the contents heated nearly to boiling, filtered. and the residue washed until the filtrate and washings amounted to $60 \mathrm{cc}$. The solution was titrated with tenth-normal hydrochloric acid at ordinary temperature, first with phenolphthalein as an indicator, then to the point of complete neutralization with methyl orange as an indicator. The filter-paper and contents were placed in the platinum dish, gently ignited and weighed. After correcting for the weight of the ash of the filter-paper, the percentages of water-insoluble ash and water-soluble ash were calculated. Excess of tenth-normal hydrochloric acid was added to the residue in the dish, the solution heated gently, cooled and titrated with tenth-normal sodium hydroxide, using methyl orange as an indicator. The three alkalinities thus obtained are known respectively as the phenolphthalein alkalinity of the water-soluble ash, the methyl orange alkalinity of the water-soluble ash and the alkalinity of the water-insoluble ash, and each is expressed as the number of cubic centimeters of tenth-normal acid used for the ash of I gram of the sample.

Method $(b)$.-The platinum dish containing the weighed total ash was nearly filled with water, then warmed gently and well rubbed with a rubber-tipped rod. The solution was titrated in the dish with tenth-normal hydrochloric acid, using phenolphthalein as an indicator. It was found that concordant results can be obtained by titrating immediately, allowing the acid to drop into the solution at a uniform rate, stirring continually, and noting the volume run in when the solution first becomes colorless. The 
red color soon returns, but the first reading should be the one used. An excess of acid was then added, using at least $2 \mathrm{cc}$. for each milligram of ash, the solution transferred to a small beaker, care being taken to dissolve out all the ash, and titrated with tenthnormal sodium hydroxide. The two alkalinities thus obtained are known respectively as the phenolphthalein alkalinity of the watersoluble ash and the total alkalinity of the ash, and each is expressed as the number of cubic centimeters of tenth-nomal acid required for the ash of $\mathrm{I}$ gram of the sample. The phenolphthalein alkalinity values obtained by methorls $(a)$ and $(b)$ agree very closely, and the sum of the two methyl orange alkalinities obtained by method $(a)$ obviously equals the total alkalinity obtained by method $(b)$.

\section{DISCUSSION AND FURTHER ANALISES.}

Polariation.-As a rule, the pure maple-syrups and sugars show less dextro-polarizations and greater lacvo-polarizations than are shown in the adulterated samples, and a common characteristic noted in samples to which cane-sugar has been added is the closer agreement between the sucrose values and the direct polarization readings. In twenty-one samples among the pure maple-syrups and in seventeen samples among the adulterated syrups the sucrose values exceed the direct polarizations, but in the former class the differences range from I.49 to 5.I I, while in the latter class the range is from 0.1 I to 2.82 . A similar comparison can be macle among the results obtaned on the sugars. A close concordance is not shown between the polarization peculiarities and the percentages of reducing sugars.

Reducing Sitgars.-The reducing sugars in the pure syrups range from 0.60 to 0.17 per cent., and in the pure sugars from I.16 to 8.37 per cent. The highest reducing sugar found was in an adulterated syrup, which showed 12.47 per cent. The percentage of reducing sugar is, when taken alone, not a criterion as to purity, and may be related to other causes than adulteration with glucose. In Table VI are given the results obtained in an experiment in which a sample of pure maple-syrup was subjected to a series of boilings covering a total time of forty-five hours. The analyses were macle at five-hour intervals. Three months elapsed between the thirty-hour and thirty-five-hour periods, and in the meantime the sample fermented. The sample was boiled in a flask connected with a reflux condenser. 
TABLE VI.-RESULTS OF BOILING EXPERIMENT.

\begin{tabular}{|c|c|c|c|c|c|c|c|}
\hline \multirow[b]{2}{*}{$\begin{array}{l}\text { Time. } \\
\text { Hours. }\end{array}$} & \multicolumn{2}{|c|}{ Polarization. } & \multirow[b]{2}{*}{$\begin{array}{l}\text { Sucrose. } \\
\text { Per cent. }\end{array}$} & \multirow{2}{*}{$\begin{array}{c}\text { Reducing } \\
\text { sugar. } \\
\text { Per cent. }\end{array}$} & \multirow{2}{*}{$\begin{array}{c}\text { Total } \\
\text { sugar. } \\
\text { Per cent. }\end{array}$} & \multirow{2}{*}{$\begin{array}{c}\text { Sucrose in } \\
\text { total } \\
\text { sugar. } \\
\text { Per cent. }\end{array}$} & \multirow{2}{*}{$\begin{array}{l}\text { Reducing } \\
\text { sugar in } \\
\text { total sugar. } \\
\text { Per cent. }\end{array}$} \\
\hline & Direct. & Invert. & & & & & \\
\hline . & Original & sample & 40.35 & 1.67 & 42.02 & 96.01 & 3.99 \\
\hline 5 & +38.0 & -14.5 & 39.47 & 2.35 & 41.82 & $94.3 \mathrm{I}$ & 5.69 \\
\hline Io & +36.0 & -13.6 & 37.15 & 3.60 & 40.75 & 91.16 & 8.84 \\
\hline I5 & +34.0 & -12.2 & $34 \cdot 73$ & 6.04 & 40.77 & 85.18 & 14.82 \\
\hline 20 & +26.9 & - II 8 & 29.10 & II. I 2 & 40.32 & 74.07 & 25.93 \\
\hline 25 & +20.2 & $-\mathrm{II} .2$ & 23.43 & 17.09 & 40.52 & 57.82 & 42.18 \\
\hline 30 & +14.0 & $-\mathrm{I} I .2$ & I 8.82 & $2 \mathrm{~T} .44$ & 40.26 & 46.77 & 53.23 \\
\hline 35 & +2.5 & -11.2 & I0. 76 & 26.75 & 37.51 & 28.69 & 71.31 \\
\hline 40 & -4.5 & $-13 . I$ & 6.57 & 30.89 & $37 \cdot 46$ & 17.54 & 82.46 \\
\hline 45 & -9.0 & -10.2 & 0.28 & 37.25 & 37.53 & 0.78 & 99.22 \\
\hline
\end{tabular}

Lead Subacetate Precipitate.-The precipitates vary in the pure syrups from 0.94 to $\mathrm{I} .82 \mathrm{cc}$, and in the pure sugars from $\mathrm{I} . \mathrm{I} 8$ to $4.4 \mathrm{I} \mathrm{cc}$. The highest results, especially among the sugars, are apt to occur in samples which have not been properly clarified. In well clarified samples the precipitates will be found, as a rule, between I.00 and I.20 cc. for syrups, and between I.20 and $2.00 \mathrm{cc}$. for sugars. Dilution by adding cane-sugar brings the precipitate values down, a point well illustrated by the results shown in Tables II and IV. The precipitates given by the pure samples were commonly white or very light gray in color, while the supernatant liquid, in practically every case, was clear and colorless. Distinct dark colors have often been observed when making tests on adulterated samples, and these colors have been shown to be due to the presence of caramel.

Protein.-These results are of interest, although they are obtained by a more complete analysis than is usually called for in practical work. The percentages in the pure syrups range from 0.223 to 0.334 (excluding 0.408 obtained on 4 Penn.), and in the pure sugars from 0.320 to 0.816 . The results on the adulterated samples are not as low as would be expected in some cases, yet they are, in the main, concordant with the results obtained by the other determinations. The protein content may be lowered by two operations, first by clarification, second by dilution with canesugar. It may, therefore, be seen that the protein percentage alone furnishes a clue as to the character of a given sample.

Malic Acid V alue.-This determination affords interesting data, and is of great value in doubtful cases. The results on the pure syrups range from 0.84 to 1.28 (excluding 1.76 obtained on 
4 Penn.), and on the pure sugars from 0.98 to 1.67 . When the results fall below these minimum values there is evidence of adulteration with cane or so-called brown sugar. A good case in point is sample No. 480 in Table IV, in which the malic acid value is $0.3 \mathrm{I}$, while the percentage of ash is 1.76 . The presence of brown stgar is further indicated in this sample by the relatively low lead subacetate precipitate, also by the high $\mathrm{K}_{2} \mathrm{O}$ in comparison with the low $\mathrm{CaO}$. It is safe to say that in the majority of cases the malic acid value furnishes absolute eviclence as to whether a sample contains brown sugar. The malic acid values for the brown sugars, tabulated in Table IX, vary from 0.08 to 0.18 .

Ash.-The determination of ash is of especial value both as a means of deciding upon the general character of a sample and in detecting adulteration. Unclarified samples are much less uniform in composition than clarified samples, hence the percentages of ash among the former will show wicler variations than among the latter. The ash results obtained on pure clarified maple-syrups and sugars should vary within narrow limits. The tabulated results show a variation among the pure syrups from 0.52 to 1 . 0 I per cent., and among the pure sugars from 0.65 to $\mathrm{I} .30$ per cent. An inspection of the tables, however, shows that the variation among pure clarified samples is not so great, that the proper range for syrups is from 0.52 to about 0.75 per cent., and for sugars from 0.65 to about 1.00 per cent. Percentages of ash furnish, also, fairly definite values upon which to base estimates of the extent of adulteration with cane-sugar. and in making such estimates, say in the case of syrups, it is very fair to assume 0.50 per cent. as the minimum for ash. A safe estimate could be made in the majority of cases, using 0.60 per cent. as representing the ash of an average pure maple-syrup.

Table VII shows results obtained by a quantitative analysis of samples of ash prepared from syrups and sugars of known purity. The results obtained on a sample of brown sugar are also given for comparison. In preparing the ash about 200 grams of syrup or sugar were taken, and the operation carried out by ashing portions of the sample separately. The material was heated in a large platinum dish over an asbestos plate to the point of carbonization, the mass carbonized at low heat, the soluble salts then dissolved in 
hot water, filtered and washed out. The residual mass was burned until free from carbon, the solution of the soluble salts added, the whole evaporated to dryness on a water-bath, then, after being gently ignited, placed in a glass-stoppered weighing bottle for future use. The determinations were made by the usual approved methods employed in quantitative analysis.

TABle VII.-CoMposition OF ASH OF MAPLE-SYRUP AND SUGAR.

Samples. $\begin{gathered}\text { Silica and } \\ \text { sand. }\end{gathered} \mathrm{CO}_{2}$. CaO. MgO. $\mathrm{Mn}_{8} \mathrm{O}_{4}, \mathrm{~K}_{2} \mathrm{O} . \quad \mathrm{Na}_{2} \mathrm{O} . \mathrm{SO}_{3} . \mathrm{P}_{2} \mathrm{O}_{5} . \quad \mathrm{Cl}$. $\begin{array}{lllllllllll}\text { Minnesota syrup } & 2.25 & 30.86 & 18.60 & 4.65 & 0.75 & 31.58 & 6.86 & 2.31 & \text { I.64 } & 0.09\end{array}$ $\begin{array}{llllllllllll}\text { Penna. syrup... 2.I7 } & 28.70 & 20.35 & 4.16 & 2.22 & 30.87 & 4.01 & 2.42 & 4.67 & \ldots\end{array}$ $\begin{array}{lllllllllll}\text { Vermont sugar } \cdot 9.77 & 30.22 & 23.05 & 2.54 & 0.45 & 28.37 & 2.84 & \text { I.15 } & \text { 1.18 trace }\end{array}$ $\begin{array}{llllllllll}\text { Vermont sugar * } 4.48 & 30.79 & 20.62 & 3.75 & 0.50 & 33.06 & 3.56 & 1.77 & 1.24 & \text { trace }\end{array}$ $\begin{array}{llllllllllll}\text { Brown sugar.... } & 2.30 & \ldots & 15.63 & 4.72 & \text { none } & 40.62 & 2.3^{6} & 4.5^{8} & 0.3^{2} & 0.3^{\circ}\end{array}$

The high $\mathrm{P}_{2} \mathrm{O}_{5}$ result obtained on the Pennsylvania syrup ash is unexpected, yet the result is apparently correct. The result for $\mathrm{CO}_{2}$ on the brown sugar ash was unsatisfactory, hence is omitted.

The color of the ash of a maple-syrup or sugar is an interesting property. An almost constant indication is a more or less distinct green color, the intensity of which varies partly with the degree of purity of the sample. The ash obtained from the Minnesota syrup of Table VII was especially noticeable, the completely ignited sample presenting a distinct purple hue and imparting a decided color to the water solution. The results given in the above table show the presence of manganese in all samples with the exception of the ash of the brown sugar. The characteristic green color is doubtless due to the presence of manganates formed by the fusion of manganese with the potash. The green mass dissolves in a small quantity of cold water to a green solution. When this solution is either acidified, or warmed, or even highly diluted with water, its color changes from green to pink, owing to the conversion of manganate to permanganate.

The high $\mathrm{SO}_{3}$ result obtained on the brown sugar ash, shown in Table VII, raised the question as to another possible distinction between maple-sugar and brown cane-sugar. The results in Table VIII have been obtained by repeated trials, and show the extent to which this point has been investigated in this laboratory to date. Results are expressed as per cent. on the whole sample. 
Table VIII, - $\mathrm{SO}_{3}$ in Brown Sugar, Maple-Sugar, and Maple-Syrup. Brown sugars.

Maple-sugars

Maple-syrups.

(I) Very light 0.026

(2) Medium 0.064

2 Penn., I903

0.019

2 N. Y., 1904

0.033

(3) Medium

0.058

2 Vt., $\quad$ rgo4

0.025

6 Penn., I904

0.036

(4) Dark

0.059

2 N. H., I904

0.018

I Minn., I 904

0.023

O, N. Y., I903

0.014

2 Conn., I9O4

0.026

2 Conn., 1904

0.022

Mean, $\overline{0.052}$



0.029

No explanation can be given for the fact that the results obtained on the syrups exceed those obtained on the maple-sugars.

In Table IX are shown results of a partial analysis of the four samples of brown sugar included in the preceding table. The chief characteristics shown are, first, very low malic acid values, second, low precipitates in relation to high percentages of ash. It has also been noted that the ash of brown sugar is sometimes difficult to decarbonize, owing to the large amount of fused potash present, and is finally decidedly white.

TABLE IX.-RESULTS OBTAINED ON BROWN SUGARS.

\begin{tabular}{|c|c|c|c|c|c|c|c|}
\hline  & 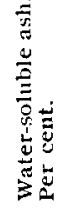 & 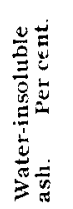 & 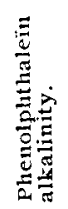 &  & 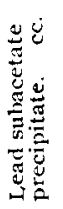 &  &  \\
\hline light 0.59 & 0.46 & 0.13 & O. I 5 & 0.32 & 1.03 & 0.321 & 0.08 \\
\hline 1.. 1.65 & I. 23 & 0.42 & 0.29 & 0.43 & I. 20 & 0.340 & 0.10 \\
\hline $\mathrm{I} .8 \mathrm{I}$ & 1.42 & 0.39 & 0.36 & 0.44 & I. 45 & 0.422 & o. 18 \\
\hline 0.85 & 0.64 & $0.2 \mathrm{I}$ & 0.23 & 0.39 & 1.25 & 0.393 & 0.18 \\
\hline
\end{tabular}

(I) Very light 0.59

(2) Medium.. 1.65

(3) Medium.. I.8I

0.64

$0.2 \mathrm{I}$

0.23

0.39

O. I8

Alkalinity of Ash.--As will be seen from Table VII, the composition of the ash of maple-syrups and sugars is characteristic. The ash consists chiefly of the carbonates of potassium and calcium, hence, as might be expected, the alkalinity, whether with phenolphthalein or with methyl orange, is characteristic and may be treated as an indication of the purity of a sample. The phenolphthalein alkalinities among the pure maple-syrups range from 0.20 to $0.4 \mathrm{I}$, and among the pure sugars from 0.23 to 0.54 ; with the total alkalinities the range is respectively from 0.73 to $\mathrm{I} .5 \mathrm{I}$, and from $I_{.03}$ to 2.14. The $\mathrm{K}_{2} \mathrm{O}$ and $\mathrm{CaO}$ results shown in Tables I to IV are estimates based on the titrations, and, while close accuracy is not claimed for them, they are given as a matter of general interest. 
Effect of Clarification.-In the manufacture of maple-syrup and sugar the mineral and organic substances contained in solution in the sap are only partly separated from the finished product. Interesting results have been obtained by a series of filtering and boiling experiments, the purpose of which was to obtain data showing the changes in general composition occurring in a syrup during the process of clarification. The results are shown in Table X, and need no explanation further than that the syrups were made in the laboratory from known-pure maple-sugar stock.

TABLE X.-RESUL,TS OBTAINED ON FILTERED AND BOILED SYRUPS.

Description.

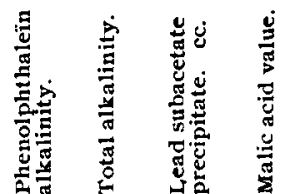

Syrup made from early sugar (sp. gr. 1.300 ) .. Filtered through linen cloth ............... Filtered through S. \& S. 575 hardened paper.. Boiled 7 brs. and filtered through S. \& S. 575 Syrup made from late sugar (sp. gr. 1.3 2 ) ... Filtered through felt only.............. Filtered through S. \& S. 575 only.......... Same boiled and filtered through S. \& S. 575 .. Syrup made from late sugar (sp. gr. I.253) ... Filtered through felt only................ Filtered twice through S. \& S. 575 only...... Same boiled and filtered through S. \& S. 575 .



$\begin{array}{lll}0.80 & 0.29\end{array}$

$\begin{array}{lll}0.72 & 0.28\end{array}$

$\begin{array}{lll}0.62 & 0.22\end{array}$

$0.58 \quad 0.20$

$\begin{array}{lll}1.02 & 0.27\end{array}$

$\begin{array}{lll}0.79 & 0.26\end{array}$

0.84

0.76

0.66

0.53

0.57

0.56
1.37

1.53

I. $15 \quad 1.28$

$\begin{array}{lll}0.95 & 0.96\end{array}$

$0.77 \quad 0.93$

I. $36 \quad 1.66$

$\begin{array}{lll}1.12 & 1.57\end{array}$

1.101 .60

0.91

$\begin{array}{lllll}0.23 & I .26 & I .23 & 0.79\end{array}$

$\begin{array}{llll}0.20 & 1.00 & 1.14 & 1.19\end{array}$

$0.18 \quad 0.98 \quad$ I. $10 \quad 1.08$

$\begin{array}{lllll}0.16 & 0.95 & 1.14 & 0.92\end{array}$

$\begin{array}{llll}0.15 & 0.96 & 1.14 & 0.82\end{array}$

The filtering through hardened filter-paper was accomplished by the aid of a vacuum pump.

Standards of Purity.-On account of its rapidity of execution, the first determination to make in the routine examination of maple products for adulteration is the precipitate with lead subacetate. In doubtful cases this result may be confirmed either by the determination and examination of the ash or by the determination of the malic acid value. In still more doubtful cases and in cases where litigation is involved a full analysis may be required. An inspection of the tabulated results will reveal the extent to which the moisture content of the samples is a factor affecting the magnitude of the results, and will show that standards of purity can best be found among results expressed on the 
moisture-free basis. The values tabulated in the last four columns of Tables I to IV will illustrate, and for the purpose of suggesting standards, are briefly summarized as follows:

TABLE XI.-SUMMARY OF RESUi,TS ON DRY BASIS.

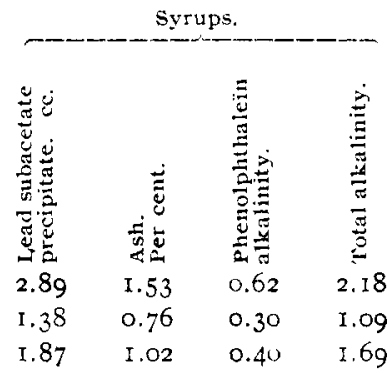

\begin{tabular}{|c|c|c|c|}
\hline \multicolumn{4}{|c|}{ Sugars. } \\
\hline 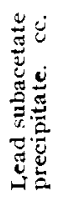 & 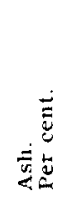 & 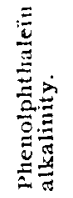 & 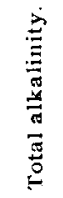 \\
\hline $3.35^{t}$ & 1.45 & 0.57 & 2.39 \\
\hline $1.3 \mathrm{I}$ & 0.72 & 0.25 & I.12 \\
\hline 1.99 & 0.99 & $0.4 \mathrm{I}$ & 1.69 \\
\hline
\end{tabular}

Color.-The more or less marked reaction with ferric salts shown by maple-syrups and maple-sugar solutions is indicative of the presence of tannin. In a few instances the reactions have been noted as slight, but in the majority of samples they have been described as distinct, normal, strong or very strong. In aclulterated samples the reactions have been similar, although in a few cases they were so indistinct as to be classed doubtful. Numerous qualitative tests have failed to give results sufficiently definite to aid one in forming an opinion as to the character of a given sample. Pure syrups, as a rule, show little loss of color on filtering through fuller's earth, while among syrups known to be adulterated the loss has often been considerable and in a few cases has amounted practically to a complete removal of the color. Taken in comparison with analytical data, the test with fuller's earth may sometimes give significant results. When the amount of coloring-matter in a sample appears to be high in relation to values which are shown to be low, the fact may be taken as a further proof of sophistication. Qualitative methods here, as elsewhere, are not wholly satisfactory, hence it is hoped in the near future to be able to devise a method by which the examination as to color can be made to furnish definite results.

In conclusion, the writer wishes to acknowledge the assistance received from Mr. F. W. Beclford, of this laboratory, who, in addition to his active interest shown in this investigation, has performed much of the analytical work. $\mathrm{He}$ is specially credited

I Three unclarified samples onitted. 
with the work on the ash alkalinities and on the malic acid values. The results on malic acid are all his. Acknowledgment is also due to Miss Clara Hillesheim for her faithful and efficient assistance in making a large number of the analyses.

LABORATORY OF MINNESOTA DAIRY AND FOOD DEPARTMENT, St. Paul, Minnesota.

\section{NOTES.}

An Experiment Illustrating Osmosis.-If one places an ordinary hen's egg in concentrated hydrochloric acid for a few minutes, the shell is removed and the egg is left in its original shape, surrounded by an excellent semi-permeable membrane.

If now the egg is placed in a beaker of pure water, it will swell up very markedly. For example, an egg weighing 57.8 grams, shelled as indicated, increased in weight in twenty-four hours to 79.0 grams, and in larger circumference from 15.5 to $18.5 \mathrm{~cm}$.

If the egg is placed in a saturated solution of calcium chloride, it will diminish in size just as strikingly. For example, an egg weighing 50 grams decreased in weight in twenty-four hours to 38.8 grams, and in larger circumference from 15.5 to $13.5 \mathrm{~cm}$.

For lecture purposes a very effective arrangement is to get three eggs as nearly the same size as possible, shell them as indicated and place one of them in a calcium chloride solution and the other in water, reserving the third for comparison. At the next lecture attention is called to the change in appearance. The calcium chloride egg will look as if it were cooked.

A still more striking method is to place an egg in a small beaker so that only half of it is immersed in acid. When the half shell is removed the egg is placed in water and in twenty-four hours the unshelled portion will be expanded amazingly and the portion retaining the shell will serve for comparison.

An interesting fact in this connection is that an egg from which the shell has not been removed will increase in weight very materially if placed in pure water for a few hours, but will remain otherwise unchanged.

Horace G. Byers.

UNIVERSITY OF WASHINGTON.

Preparation of Cyanacetic Ester.-Although cyanacetic ester is a substance of very considerable importance for synthetical work 